\title{
Innovative Uses of Visual Technologies in Initial Teacher Education: Changing Policy to Support Practice during COVID-19
}

Visual Technologies as a Panacea for Social Isolation

\author{
Megan Adams | ORCID: oooo-ooo1-8824-6854 \\ Faculty of Education, Monash University, Melbourne, Australia \\ megan.adams@monash.edu
}

\author{
Tim Brooks \\ Mount Zaagkam School / Sedbergh, Cumbria, England \\ timb916@gmail.com
}
Angela Fitzgerald | ORCID: oooo-0oo1-8010-2215
University of Southern Queensland, Toowoomba, Australia angela.fitzgerald@usq.edu.au

\author{
Sindu George | ORCID: oooo-0oo3-3776-9705 \\ Faculty of Education and Arts, St Patrick's Campus, Australian Catholic \\ University, Melbourne, Australia \\ sindu.george@acu.edu.au \\ Rebecca Cooper | ORCID: OOOO-0002-2421-7488 \\ Faculty of Education, Monash University, Melbourne, Australia \\ rebecca.cooper@monash.edu
}

\begin{abstract}
In Australia, schools and faculties of education are mandated to abide by a policy requiring preservice teachers (PST S), to complete supervised professional placement $(\mathrm{PE})$ in schools. The PE are drawn upon to meet the assessment criteria for degree completion. Two strategies are reported that supported individuals and education institutions to meet policy requirements while in lockdown. First, technology was


used to overcome the challenge of providing PE for hundreds of PST s by supporting online learning experiences. In the second, visual technologies were used to support PST s to meet the needs of an assessment criterion. Findings indicate that innovative solutions to challenges with $\mathrm{PE}$ and related assessments at the university can be mobilized in a short time frame using visual technologies. Further findings indicate that, in unprecedented times, policies developed for use in different contexts can be met with innovative collaborative efforts with a focused goal that transcend seemingly insurmountable challenges.

\section{Keywords}

visual technologies against social isolation - visual technologies - Initial Teacher Education - preservice teachers - professional placement - innovation - Covid-19 - pandemic

- This article is part of the special topic 'Visual Technologies as a Panacea for Social Isolation', edited by Rene Novak.

\section{Introduction}

A core objective of Initial Teacher Education (ITE) programmes is to ensure preservice teachers (PSTs) graduate with the capabilities to work and educate in a globalized world. Professional placement is at the heart of ITE programmes, providing PST s with structured opportunities to practise and engage in authentic and active approaches to teaching and to relate practice to the knowledge and understanding they develop through their programme. ITE in Australia, the context for this study, is required to offer sixty to eighty days of supervised professional placement experience in which PST s observe and undertake a wide range of teaching and non-teaching activities in situ, thus developing an appreciation for the complexity of teaching and the roles of teachers. Importantly, as a response to the global pandemic, a policy decision was made by most of the state and territory teaching regulatory authorities in Australia to reduce the required professional experience days to forty-five days for PST s graduating in 2020. The mentor teachers at the placement schools and teacher educators moderate these reciprocal learning opportunities through which the PSTs realize the consonance between theory and practice. In other words, these institutional practices contribute to the PST s' professional learning and development. However, the global pandemic and the current 
circumstances have adversely affected the placement practice opportunities. This article discusses how teacher educators called upon visual methodologies to creatively find a solution to the inability to engage PST s in traditional face-to-face professional placement experiences.

\section{Theoretical Framework}

Hedegaard $(2008,2012)$ proposed a holistic model of children's learning and development based on Vygotsky's cultural-historical theory. Although directed towards children, the model is transferable across contexts, and in the current study, we extend the model to examine the use of various forms of visual technology to support PST $\mathrm{s}$ in meeting course requirements when face-to-face contact was limited because of CoviD-19. According to Hedegaard, societal laws and policies and the application of resultant practices at the institutional level place demands on participation that affect individuals on a personal level. To situate Hedegaard's (2008) model, we first review the broader literature to provide a foundation and present an awareness of what is currently understood in relation to models of professional development.

There are many models of professional experience, but the most common one is PST s spending time with in-service teachers at their school to observe, plan and deliver lessons under supervision (Walton \& Rusznyak, 2013). The learning that eventuates from this professional experience depends on the way that the experience is then used as part of the ITE programme that the PST is enrolled in. Cochran-Smith and Lytle (1999) outlined two ways of considering the relationship between teacher knowledge and classroom practice: knowledge-for-practice and knowledge-in-practice. If a programme takes a knowledge-for-practice approach, the professional experience will be viewed as an opportunity to take the formal theory (knowledge) learned as part of the programme and put it into practice in a classroom environment. However, if a programme takes a knowledge-in-practice approach, professional experience will be viewed as an opportunity to embed knowledge as part of 'acting and thinking wisely in the immediacy of classroom life' (Cochran-Smith \& Lytle, 1999, p. 266). When understood this way, professional experience becomes about making the tacit knowledge used by teachers during classroom interactions explicit for PST s, who then have the opportunity to question and reflect on what it might mean for their developing knowledge and practice.

Models of professional experience generally rely on a version of mentoring in which a novice teacher is mentored by an experienced teacher (see Chien, 2015; Yendol-Hoppey \& Dana, 2007). However, it has been suggested that teachers in this mentoring role should be expert or even 'master teachers' 
(Grant, 1997) who consider teacher education 'rooted in the study of practice', to encourage a higher level of dialogue with PST s about puzzling problems of practice' (Lampert \& Ball, 1998, p. vii). After a placement experience, once PST s return to their university course, the teacher educators build on and guide the knowledge development and explore ways that theory can provide perspective on classroom practice (Craib, 1992). The models outlined above work from the premise that face-to-face contact is possible and placement experience involves a period of workplace-based learning. The key insights highlighted in these models of professional placements are represented in Figure 1.

However, because of recent experience and strict mandates regarding social isolation, both in Australia and worldwide, online learning and teaching alternatives are required that both meet policy demands and support PST s in developing their teaching pedagogy. Lampert and Ball (1998) suggested that PST s be provided with opportunities for 'pedagogical inquiry' (p. 110). Pedagogical inquiry, when described this way, could involve reading about or observing an experienced teacher's practice in a multimedia environment and then reflecting on this with the guidance of a teacher educator. In further developing this idea, research into noticing through the use of video technologies, especially in mathematics and science education (Chan et al., 2020), is useful. The current circumstances, which call for online flexibility in sustaining educational outcomes and for overall wellbeing, have raised questions and triggered changes to the widely accepted professional experience model (see Figure 1). The current study proposes a revised model that introduces digital technologies and pedagogies, policies and regulations, and teacher educators to support the development of PST s' pedagogy in this changed context. Visual

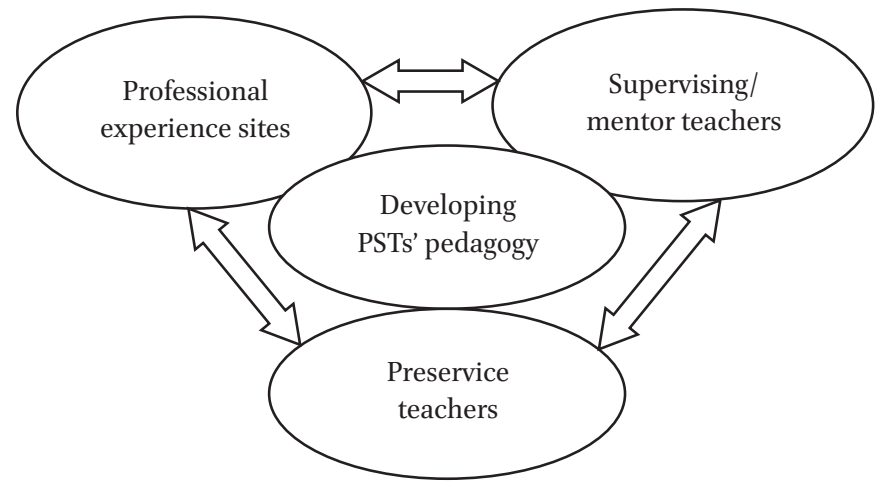

FIGURE 1 Professional Experience Model 
methodologies, in particular, are readily used by cultural-historical researchers when studying young children's learning and development (see Fleer, 2013) and are a well-developed research methodology (see Figure 2) (Fitzgerald \& Lowe, 2020; Fleer \& Ridgway, 2013; Pink et al., 2016). Teachers' Placement Experience

There are two points to consider when using the cultural-historical methodology. The first is the context, which includes the societal laws and policies that are reflected in institutional practices and the ways these practices affect individuals (Hedegaard, 2008; Vygotsky, 1998). This is interwoven with the second point, which considers a holistic approach to learning and development that emphasizes the process rather than the product (Devi et al., 2020). The process, according to Vygotsky (1997), is dynamic and encompasses all aspects of development from birth to the end of life. With the process of development as the focus, we examine the use of varying forms of visual technology to support PST s moving through their university degree in a timely manner during the crisis period of the pandemic when Australians were in 'lockdown' and unable to participate in social gatherings.

Many researchers using cultural-historical theory advocate for digital technology as a research tool (Devi et al., 2020; Fleer \& Hedegaard, 2013; Fleer \& Ridgway, 2013). They use a video methodology to capture the process of development, which is then analysed. Ridgway et al. (2016) proposed a visual narrative

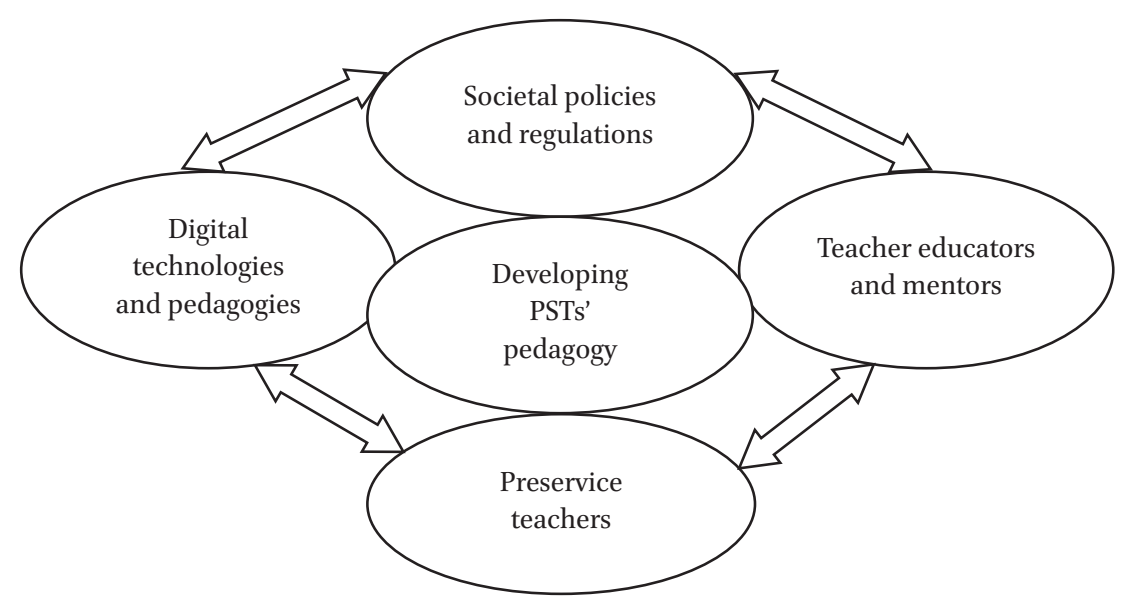

FIGURE 2 Professional Experience Model revisited 
methodology in which researchers from different cultures independently analysed a video clip, shared written responses, and then came together to discuss and further analyse the clip. Common to the use of visual technology when capturing data is the value of representing the activity in situ, where details such as emotions are recorded as they occur (Fleer, 2008). Visual technology supports highlighting different perspectives, and because of the collaborative analysis, may suppress presentation of personal bias (Goldaman, 2014). However, challenges can and do arise from the use of digital technology (Devi et al., 2020). Derry et al. (2010) indicated that misrepresentation and manipulation of differing perspectives may occur. To overcome this, as was the case in Ridgway et al.'s (2016) study, the research should be a collaborative process from beginning to end.

In the current study, we sourced data from two different visual forms that were introduced into 'dynamic workplaces with fast-changing social and material environments' (Pink et al., 2016, p. 2) due to the rapid changes brought about by COVID-19, specifically social distancing. Visual technologies were used to overcome global, social, economic and educational issues in relation to PST s' placement and completion of an assessment task related to the placement experience. Two sets of data are presented. The first set is a public interactive website, developed through a collaborative effort between the Department of Education, teachers and PST s, for students' online learning in the state of Queensland in north-eastern Australia. The second data set was captured in situ while two former colleagues on opposite sides of the world worked together to support Bachelor of Education students complete a required assignment, based on a lesson plan related to their placement experience. The two data sets are now presented, the first as a narrative and the second as a visual narrative account.

\section{1}

\section{Data Set 1}

3.1.1 Doing Professional Experience Differently: A Sectoral Approach

As the full effects of COVID-19 started to be felt in the Australian university sector, just as the academic year began, the reality dawned for ITE providers that their ability to fulfil their obligations to place PST s in educational settings was looking increasingly unlikely in 2020. In Queensland, the north-eastern state of Australia, where the third author is based as a teacher educator, seven of the nine ITE providers postponed or cancelled all their placements for Semester 1 (stretching from late February to early June), leaving thousands of PST s facing programme progression issues. 
Of particular concern were the several hundred PST s across the state who were due to graduate mid-year. This concern reverberated across the sector, and it was quickly determined that it was going to 'take a village'-a significant collaborative effort — to find some workable solutions to turn this concerning situation around.

A committed and close-knit team, comprising the heads of school from the nine ITE providers, approached the state-based Department of Education (DoE) to explore a sectoral approach to this problem. At the time, the DoE were facing their own new reality that tens of thousands of school-aged children, their parents and their teachers were about to require support to begin learning from home for an unknown stretch of time. Seeking to maintain student learning outcomes, the learning@home $(\mathrm{L} @ \mathrm{H})$ project was created. In brief, what resulted was the harnessing of significant human resources to develop a number of online tools and curriculum materials to support the self-paced learning of Prep to Year 10 students (aged five to sixteen years) in two-week study blocks across all of the key learning areas. By investing considerable human and material resources into realizing an e-learning platform, this initiative maximized the collective learning opportunities for the PSTs. A key component for the success and swift movement of this initiative was the ability to engage hundreds of PSTs, ultimately forming an alternative professional experience opportunity. Initially, the PSTs played a significant role by working with teams of teachers and educational designers via the online digital networking platform Zoom to develop lesson plans and teaching resources. Now, with the educational future still not entirely certain, the L@H project (https:// education.qld.gov.au/curriculum/learning-at-home) has been extended to include the delivery of content remotely. In both elements, the PSTs are supported by mentor teachers via digital means.

\section{2}

\section{Data Set 2}

3.2.1 Visual Technologies as a Panacea for Meeting Assignment Requirements

COVID-19 has placed many lives in limbo. For much of 2020, we have been unable to participate in everyday activities that have previously been taken for granted. Two educational opportunities that were curtailed in the first author's university in Melbourne (located in south-eastern Australia) were face-to-face university workshops and undergraduate PST s' placement experience in early childhood centres (birth to three years of age). Because of the covid-19 lockdown, only vulnerable 
children and children of essential workers were able to attend childcare, and only some childcare centres remained open, resulting in restricted or delayed placement experience.

Through using visual technology and a personal global network, the two main educational issues were overcome. Through Facebook Messenger, the first author (a university lecturer) contacted a former teaching colleague (the second author) who is employed at an international school in West Papua and working remotely from his home in Yorkshire (see Figure 3). He had been posting videos of his eighteen-month-old son's everyday life on Facebook. Permission was sought to use the videos as a teaching tool for the PST s to analyse and develop learning programmes.

\section{You sent}

Hey Tim, The reason I'm reaching out is because I'm working at a university|now and am involved in a curriculum unit in Early Childhood. I wondered if you would mind me sharing some of your videos with the students? They are meant to be having placement in an early childhood centre with birth to 2 year olds but most cannot due to COVID-19 lockdown. So I am searching for videos that I can use to introduce them to what it is like working with children under 3-4 and under. I completely understand if it is not possible.

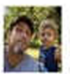

Tim

Of course!

I have a lot of video!!

If you want specific things such as reading books..playing shape games ..

Let me know what you need

FIGURE 3 Facebook Messenger correspondence between colleagues

Tim forwarded a link to a video library of his son (see Figure 4). The video collection held around 30 two-to-three minute videos of his son's everyday life, such as reading, playing in water, counting, having a bath, playing hide and seek, throwing stones, balancing and initial utterances (talking). 


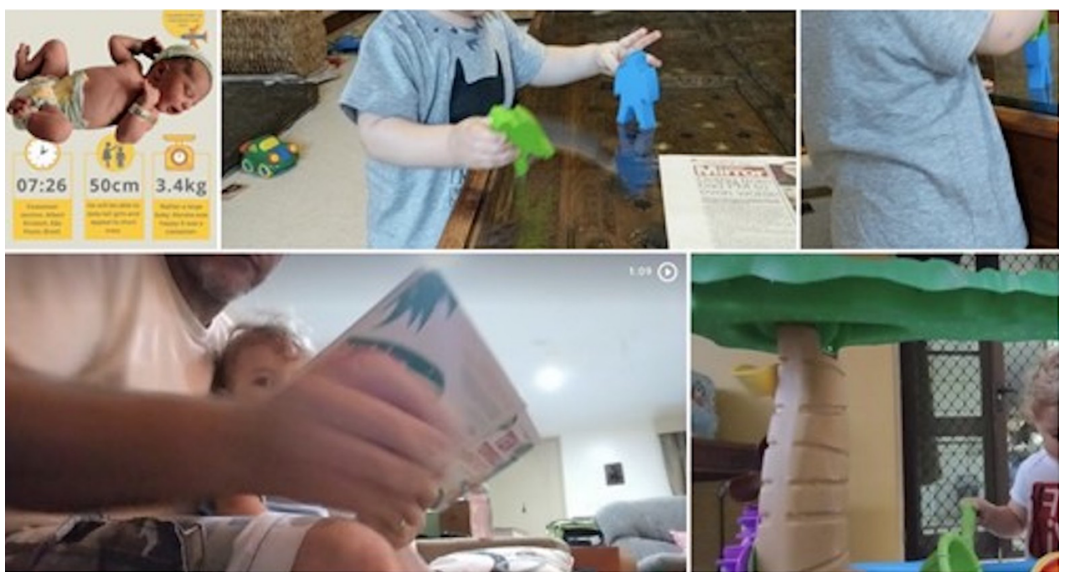

FIGURE 4 Video library

As the conversation developed, Tim agreed to join a Zoom workshop with the students (see Figure 5).

\section{You sent}

Hi Tim, Hope all is well. We are looking forward to you zooming in on Melbourne time Monday 18 th 11 am and (if not too exhausted) two hours later at lpm. Here is the zoom link which you can join from a PC, Mac, iPad, iPhone or Android device: Just click on the link or if that doesnt work, copy paste to your browser: [zoom link deleted] I've worded the students up that you will come in and discuss various areas with us. I will introduce you then you could explain your background and about your latest teaching position and the curriculum that is used in that school. You might then like to discuss what it is like with a young child compared to teaching older ones (they are Early years-Primary degree students) so this will be interesting to them. Then we can move onto more practical things like talking about emotions and how they are dealt with and what you would advise if others were dealing with your child. The assignment they need to do is look at a child playing and develop a play scenario that comes from the child's interests and then assess it (through anecdotal recording, or narrative, or time sampling - generally some form of documentation) So maybe you could talk about how you document [your sons] learning? and then how you extend it (if you do).

Tim

Yup. I'll be there...

With a flask of coffee..

Strong coffee..

FIGURE 5 Outline of workshop and agreement to join the sessions 
Tim joined the two workshops despite having to sit in his car for four hours in the middle of the night because of the time difference (between Melbourne, Australia, and Yorkshire, United Kingdom) and the inclement weather. He elaborated on teaching his own son and what it was like for him teaching young children (four- and five-year-olds) remotely in West Papua (see Figure 5). This led to discussion of the videos that Tim had made to engage the four- and five-year old children in art classes. The videos were shared with the PST s as they were developed with the children's interests in mind.

One of the videos began with Tim walking backwards and forwards across a stone-clad courtyard to the tune of 'Walk Like an Egyptian' (see Figures 6, 7 and 8). His young son joined in and copied the walking style (see Figures 9 and 10).

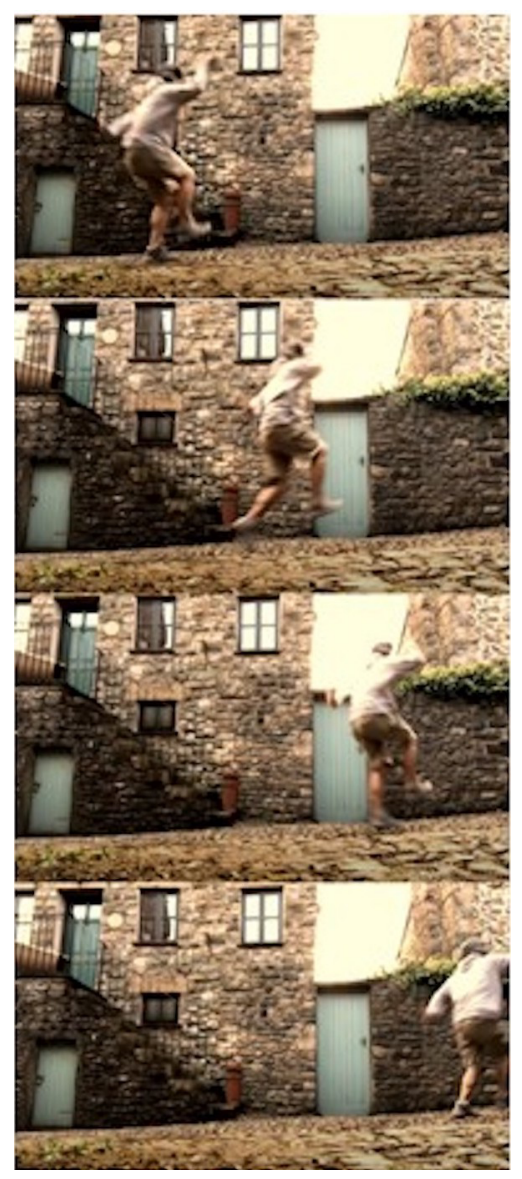

FIGURE 6 Walking like an Egyptian

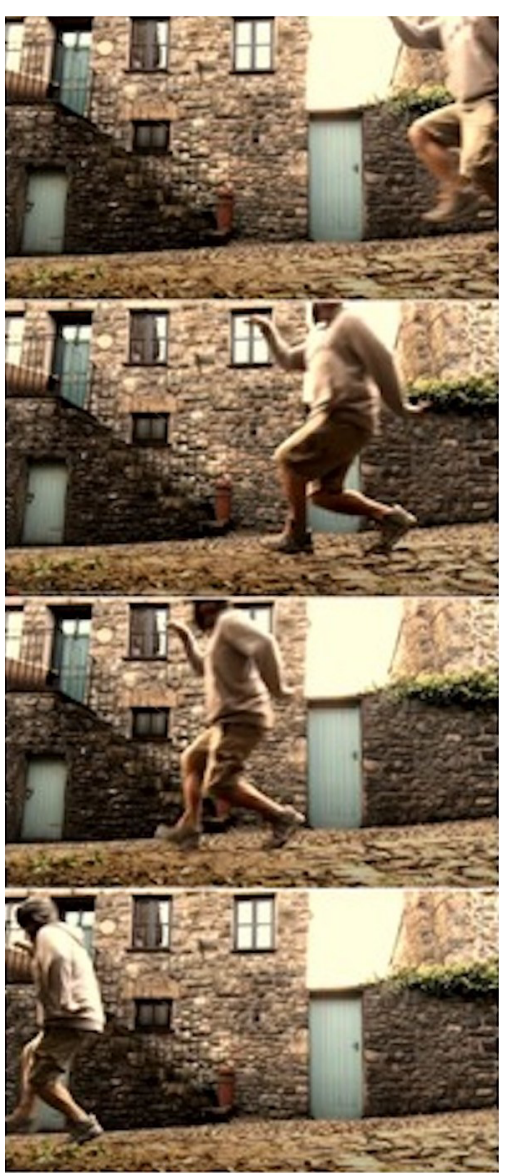

FIGURE 7 Walking like an Egyptian 


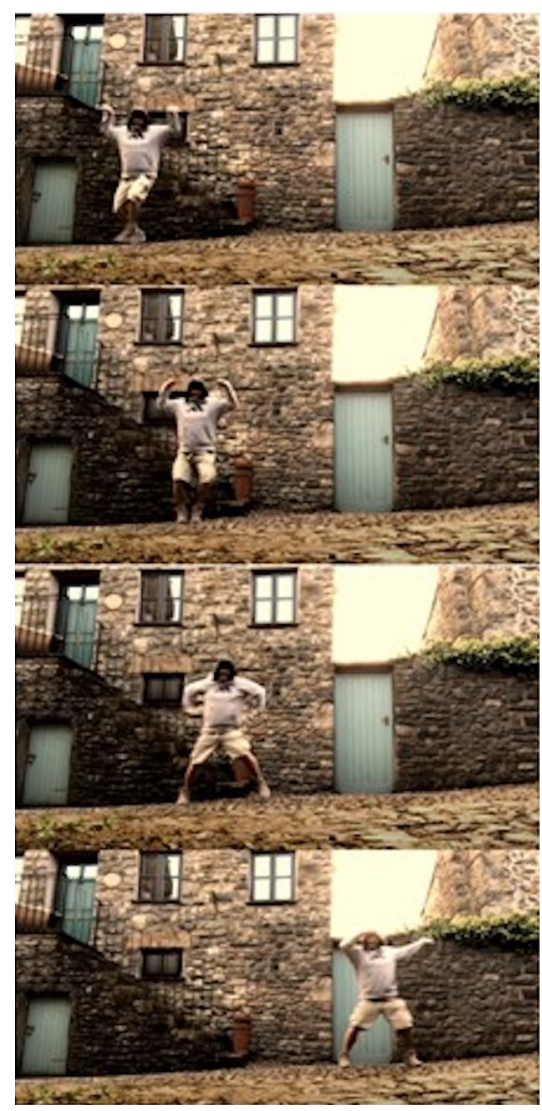

FIGURE 8 Walking like an Egyptian
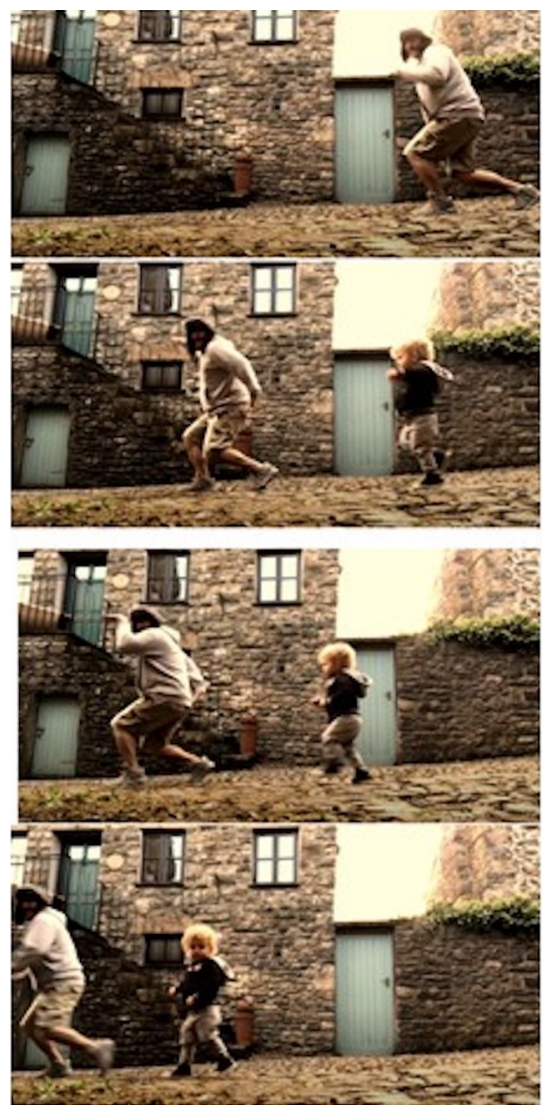

FIGURE 9 Walking like an Egyptian 


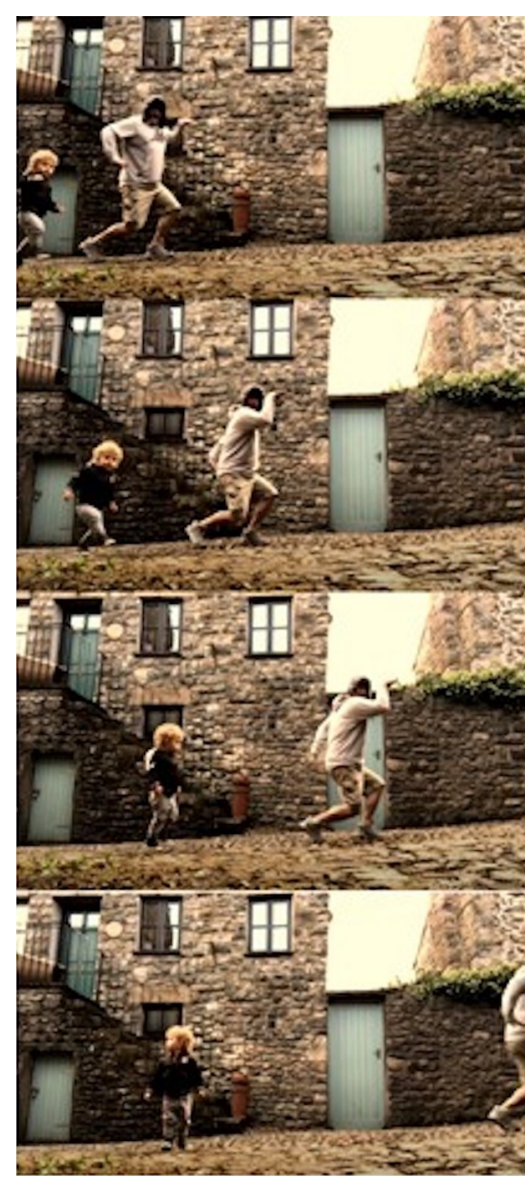

FIGURE 10 Walking like an Egyptian

The music and Egyptian walk dance were followed by an introduction to the lesson content and instructions on what the children were required to complete, which were modelled (see Figure 11) explicitly by Tim. The final scene was a repeat of the dance with Tim and his son (see Figure 12). 


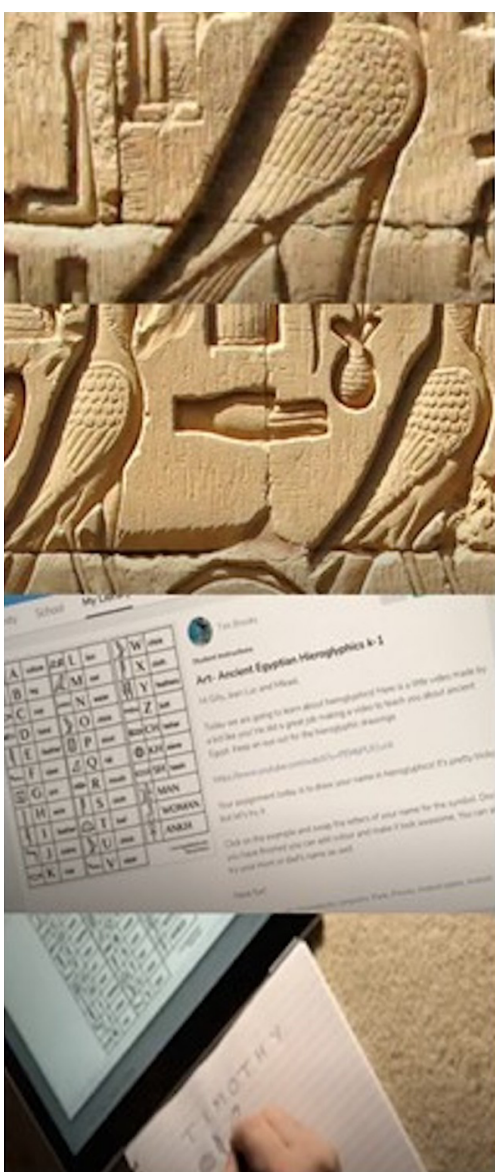

FIGURE 11 Instructions and modelling of the lesson

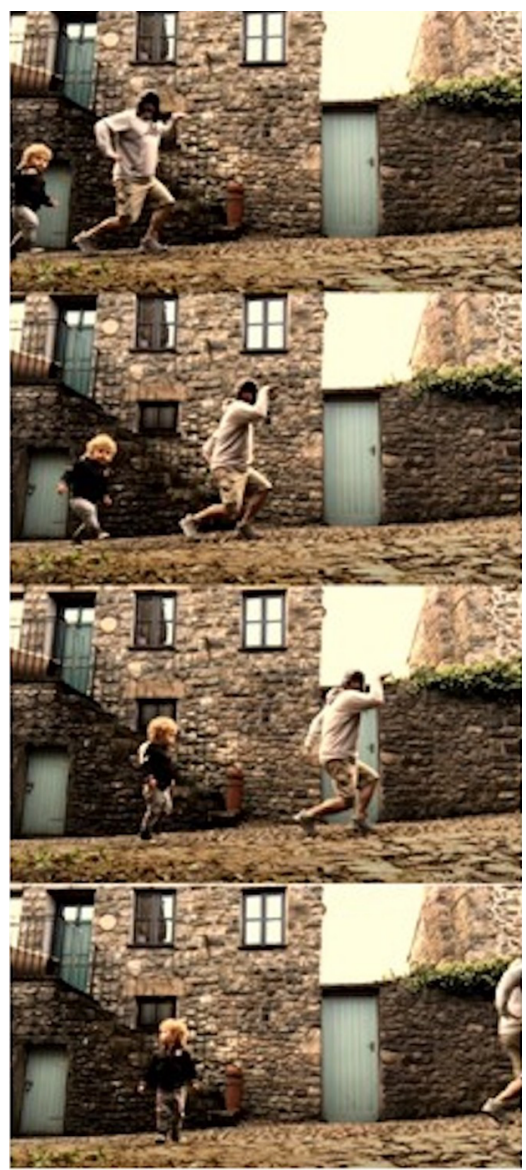

FIGURE 12 Conclusion of lesson, more dancing and copying

\subsubsection{A Time Portal}

The second video presented to the PST s concerned cave painting. Tim explained to the PST s that in any lesson there needed to be some type of 'attention grabber' at the beginning, such as music, dance or dinosaurs. Tim had also learned through feedback from parents that the videos needed to be short (no more than three minutes) with explicit instructions, both verbal and visual, so that children could watch and perform the task with little parental supervision. 
The second clip began with Tim introducing a time portal that had appeared in his courtyard (see Figure 13). A dinosaur entered his courtyard growling (see Figure 14). Tim stated, 'I hope it doesn't wake my partner and son. Quick, mind the tail. Let's go through this way' and exited through the portal to prehistoric times. He invited the audience to help him find a cave in the mountains (see Figure 14).

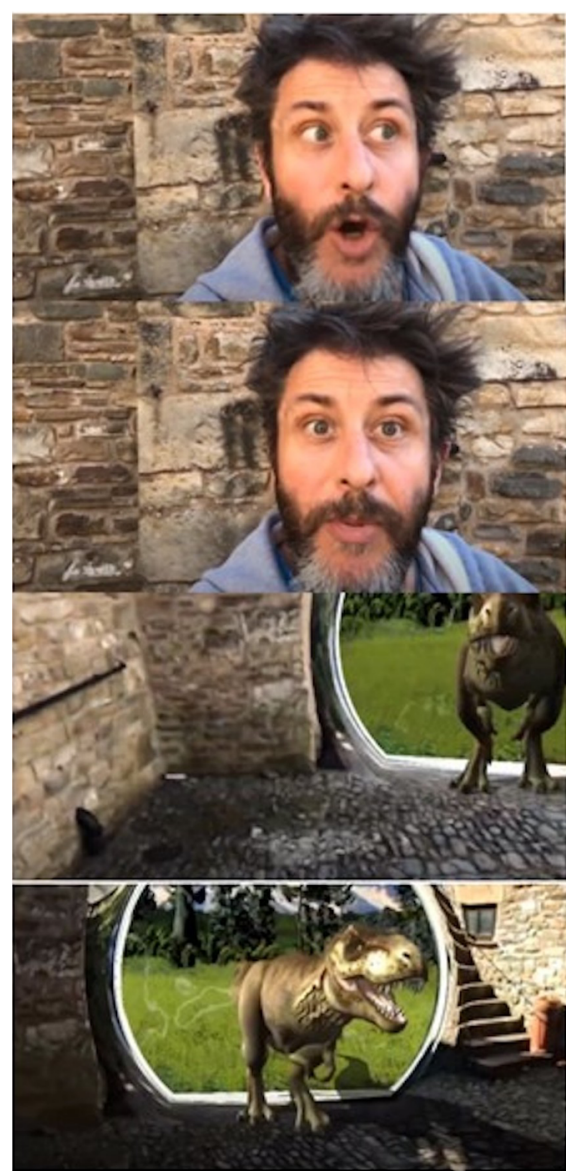

FIGURE 13 Tim introducing a time portal

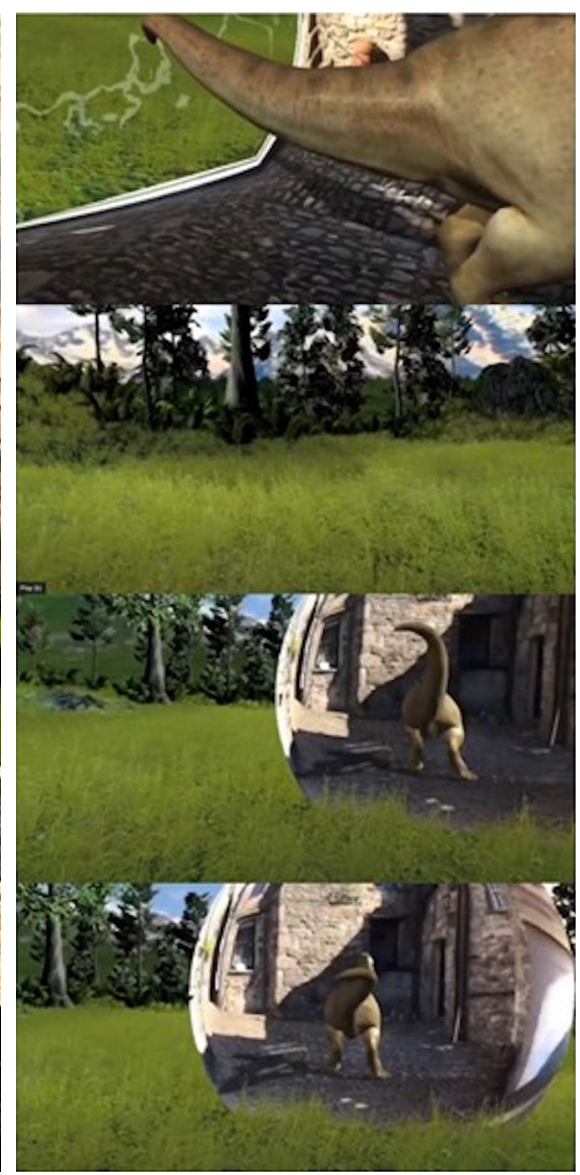

FIGURE 14 Invited the audience to help find a cave in the mountains 
The focus shifted to cave painting. Tim introduced cave paintings (see Figure 15) and indicated that the children were to draw themselves surrounded by things that they liked (see Figure 16). This was followed by the instruction to draw where they had lived, and then to draw free range on the cave wall (see Figure 17) on the iPad screen.

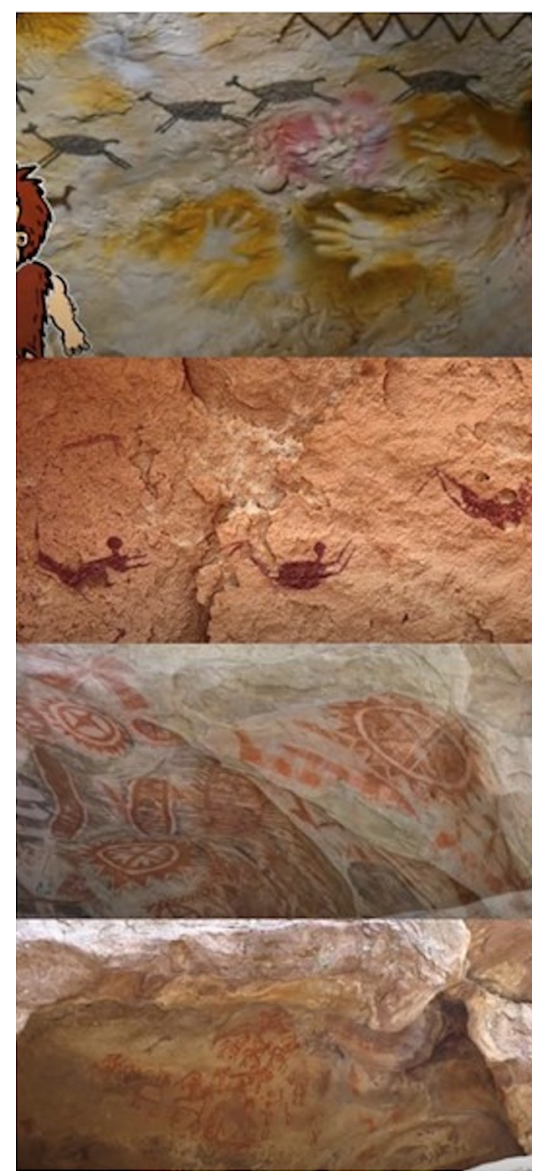

FIGURE 15 Introduction to cave paintings

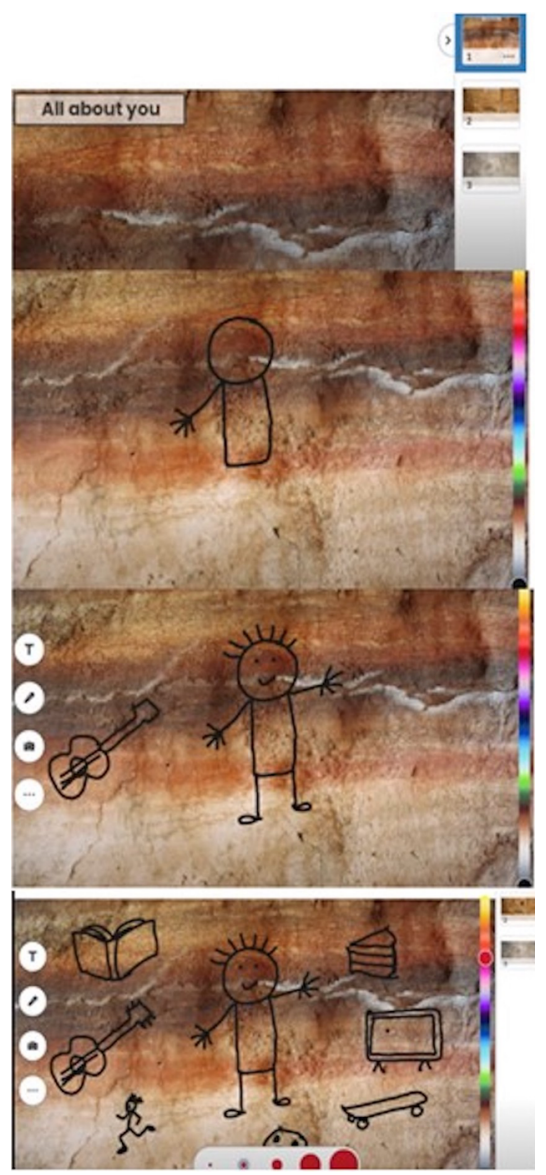

FIGURE 16 Instructions for the lesson 


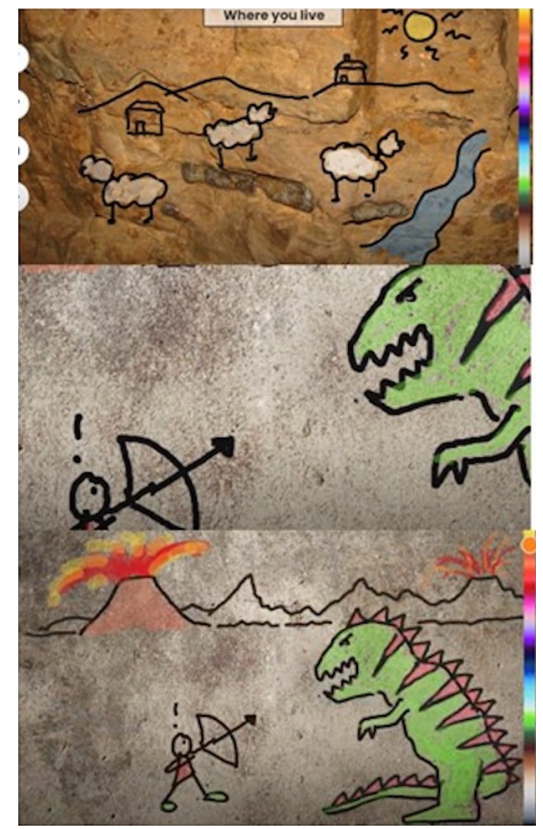

FIGURE 17 Instructions for the lesson

\section{4}

\section{Discussion}

The aim of this article was to provide insight into the varied visual technologies that are being employed to overcome educational challenges caused by social isolation. Using a Cultural-historical methodology through the application of Hedegaard's model (2008), and visual pedagogies, we have analysed the data and identified two main findings. First, in unprecedented times such as during COVID-19, policies developed for use in more 'normal times' can be met with innovative collaborative efforts with a focused goal to transcend challenges that seem insurmountable to support people facing adversity. Second, with the use of a variety of visual technologies, innovative solutions to challenges with assessments related to placement experience can provide support for learning and being proactive instead of reactive with the use of visual technology enables solutions to be mobilized in a short time frame.

As indicated by Hedegaard (2008), societal laws and policies and the application of resultant practices at the institutional level place demands on participation that affect individuals on a personal level. In this section, we have utilised these ideas as a structure to analyse the data and interpret the findings which are discussed under the headings; societal laws and policies, practices in institutions and demands on participation affecting individuals. 


\subsection{Societal Laws and Policies}

As detailed in the data sets, societal practices changed rapidly because of the pandemic, which fundamentally changed everyday teaching approaches. Because of the rapid societal changes and the direct impact on educational delivery, an initial policy change occurred in most Australian states and territories (including the two referred to in this study: Queensland and Victoria) to reduce the placement experience requirements to forty-five days of supervised practice for PST s graduating in 2020 . While this was a welcome adaptation, it did not change the policy reality for PST s graduating in subsequent years or make the reality of not being able to access school sites easier to navigate. For both ramifications, not meeting the demands of required policy constraints in relation to future graduating teachers may have long-term repercussions for the education system. The PST s would not be able to advance or graduate from their degrees, which could affect the education pipeline in which there is a natural attrition of teachers that may not be met, possibly resulting in a shortage of teachers. Similarly, the universities would need to change the current system as they would not receive funding (because of non-completion of degrees), resulting in an accumulation of students waiting for placement experience to complete their degrees.

The policy of mandating supervised placement experience, regardless of the number of days, was developed to suit a vastly different education landscape. In more normal times, as indicated in Ellis et al.'s (2013) study, policy changes tend to change organizational arrangements, structures and roles but the basic teaching practices remain the same. To work within the policy of supervised practice and meet the required practice days of placement, a novel way to include PSTs through online development of lessons was initiated through the L@H project. As indicated previously, the fully online resource was developed for Queensland students and their families to access during remote learning because of COVID-19 lockdown, although the platform was open access, allowing for the resources to be engaged with nationally and internationally. However, an unintended consequence of developing this project was the mobilization of PST s, who were mentored to develop resources and fit the requirements of their degree.

\subsection{Practices in Institutions}

The practices of institutions in turn, over time, provide evidence for policy changes and development of models of professional learning (Walton \& Rusznyak, 2013). To address the swift policy change, an innovative sectoral approach was initiated in Queensland as a way to meet the needs of PST s in relation to their required supervised placement experiences. Similarly, because 
face-to-face learning was not an option, an ITE provider in a Victorian university was required to rapidly move fully to online learning and teaching via a learning management system (Moodle) and workshops via Zoom. In addition, the PST s were restricted in attending their placement experience, including some PST s being placed in early childhood centres for limited days or their placement being delayed or cancelled. This caused additional adversities because the assignment for their university course was based on their placement experience with children aged under four. Thus, practices needed to be changed that affected the way individuals participated, including the way they experienced placement, learning and teaching and assessment. In the case of institutions that were part of this study, many of these changes involved inclusion of visual technologies.

\subsection{Demands on Participation Affecting Individuals}

Drawing on Hedegaard's (2008) model, from the individual's perspective, the demands placed on PST s to meet the assignment requirements at university were restricted, which disrupted practice in the unit. To support the PST s' pedagogical inquiry (Lampert \& Ball, 1998), various digital video pedagogies (Pink et al., 2016) were introduced (see Table 1).

Table 1 outlines six modes of visual technologies that supported PST s' learning. Initially, the teacher educator contacted a colleague through Facebook Messenger. The PST s were provided with links to the everyday life and learning experiences of a young child through videos (see Figure 4), which were used as provocations in the workshops to interpret, develop and understand the type of activities an eighteen-month-old child may undertake. To further deepen the learning and make the tacit knowledge of a teacher explicit, a practising teacher was invited to participate in online discussions to guide the knowledge development and merge theory with practice (Craib, 1992). The practising teacher shared videos that were used as a teaching resource for the teacher's classes (see Figures 6 to 17). The videos were also used as provocations in the university workshops for discussions to support the PST s' developing pedagogies to further support young children's learning across the curriculum. The PST s were encouraged to integrate their understanding into their assignment. The use of visual technology in this instance also supported the PST s in meeting the requirements of their degree.

Hedegaard's model (2008) has provided us with a framework to show the links between the required changes in policy due to covid (particularly around professional experience), that necessitated the changes in practice (inviting the inclusion of visual technologies) at the institutional level and how these affected participation (especially around assessment) at the personal level. To 
TABLE 1 Visual technologies used to support PST s with their assignment completion

\begin{tabular}{l}
$\begin{array}{l}\text { Visual technologies Pedagogical rationale Interaction } \\
\text { used }\end{array}$ \\
\hline
\end{tabular}

\begin{tabular}{lll} 
Facebook Messenger & $\begin{array}{l}\text { Initiate contact and organize work- } \\
\text { shop and follow up feedback after } \\
\text { the workshop }\end{array}$ & Personal \\
\hline $\begin{array}{l}\text { Still images } \\
\text { (Figure 4) }\end{array}$ & $\begin{array}{l}\text { Used as a provocation to interpret } \\
\text { the everyday life of a young child }\end{array}$ & $\begin{array}{l}\text { Individual } \\
\text { and learning } \\
\text { environment }\end{array}$ \\
$\begin{array}{l}\text { Video recordings: } \\
\begin{array}{l}\text { Everyday life of } \\
\text { a young child } \\
\text { (Figure } 4)\end{array}\end{array}$ & $\begin{array}{l}\text { Develop an understanding of an } \\
\text { eighteen-month-old's everyday life } \\
\text { and activities in situ }\end{array}$ & $\begin{array}{l}\text { Individual } \\
\text { and social } \\
\text { interaction }\end{array}$ \\
\hline
\end{tabular}

(Figure 4)

$\begin{array}{lll}\begin{array}{l}\text { Video recordings: } \\ \text { Examples of online } \\ \text { lessons (Figures } 6 \\ \text { to 17) }\end{array} & \begin{array}{l}\text { Making tacit knowledge explicit. } \\ \text { Child's everyday experience, prac- } \\ \text { tice informing theory informing } \\ \text { practice (examples provided) }\end{array} & \begin{array}{l}\text { Individual } \\ \text { and learning } \\ \text { environment }\end{array} \\ \begin{array}{l}\text { Zoom discussions: } \\ \text { Online real time } \\ \text { and recordings } \\ \text { for review of } \\ \text { discussions }\end{array} & \begin{array}{l}\text { Throughout online recordings, } \\ \text { tacit knowledge was made explicit } \\ \text { through discussions with expert }\end{array} & \begin{array}{l}\text { Social } \\ \text { interaction }\end{array} \\ & \begin{array}{l}\text { teacher and teacher educator and } \\ \text { example drawn upon of moving } \\ \text { everyday child's practice to theory } \\ \text { to develop teaching practice }\end{array} & \\ & \begin{array}{l}\text { Access unit weekly content, } \\ \text { required readings, video links, writ- } \\ \text { ten discussion forum }\end{array} & \begin{array}{l}\text { Individual, } \\ \text { group } \\ \text { (forum) } \\ \text { learning system }\end{array} \\ & & \begin{array}{l}\text { reciprocal } \\ \text { practices } \\ \text { (comment- } \\ \text { ing on each } \\ \text { other's posts } \\ \text { and learning } \\ \text { from Zoom }\end{array} \\ & & \text { Workshops) }\end{array}$


make the connections between the societal policies, the institutions and the individual clear, the analysis of visual pedagogies (Fleer \& Ridgway, 2013) enabled a broader perspective to be presented. In the first example, (data set 1) when mobilising large numbers of PST s to meet the requirements of their degree, engaging with visual technologies to learn about curriculum development was essential. The process that PST s and their mentors went through to develop a visual pedagogical tool in the form of a website, in turn enabled school students to access learning remotely. In this instance, the visual pedagogical product (website) enabled the process of learning to continue and be fed forward to school students. The iterative process of learning with and from others with the use of tools is foundational to learning and development at any age (Vygotsky, 1997).

In the second example, (data set 2) where a practicing teacher was invited to share knowledge and practical experience, analysis of the teaching and learning process was made possible once again, through the use of varied visual technologies. The visual narrative methodology put forward by Ridgway et al. (2016) supported analysis of the integration between technological and visual pedagogies with PST s online learning during the pandemic (see Table 1.). We support Fleer's (2008), claim, that the value of representing the pedagogies in real time through visual means, enabled analysis of the processes of learning, in this instance, the supports put forward for PST s enabled continued learning throughout the lockdown. In addition, drawing on Ridgway et al. (2016), the analysis of visual technology supported drawing together different researcher's perspectives that enabled a deeper understanding of work place practices that encompass visual pedagogies (see Table 1). In this instance, drawing together Hedegaard's model and Ridgway et al's (2016) methodological tools supported a novel way to analyse data from the policy level through to the outcomes of practice that supported individual's learning and development. Our contribution to extending the literature rests with bringing together the different contexts, (data sets 1 and 2) and using rich theoretical and methodological tools to analyse the data which was captured in a dynamic, and changing online social and material environment during the first lockdown in Australia.

\section{5}

\section{Conclusion}

Teaching is an interpersonal endeavour. Professional experience provides a necessary platform for PSTs to observe and apply the skills and knowledge that they have learned, adapt to the organizational climate by adjusting with the physical conditions and social environment of the institution, and learn 
by interacting with practising teachers and students. While we acknowledge that visual technologies are not a replacement for the learning experiences that take place in a physical classroom, we have discussed in this article how teacher educators initiated some innovative and strategic shifts at both sectoral and institutional levels to address the educational crisis caused by the global pandemic. Hedegaard's (2008) model provided a framework to bring together and analyse the two data sources. Although small scale, the current study proposes a revised professional experience model (see Figure 2) integrating visual methodologies (visual technology; see Table 1), societal policies and regulations, teacher educators and developing PSTs' pedagogy, which extends the current understanding of ITE.

Despite the social distancing and restrictions, visual methodologies ensured individual and social interaction through engagement with visual learning prompts (videos and photos), use of an interactive website, and discussion using online platforms. It was the growth mindset and broader perspective about the value-add of online learning and teaching that drove teacher educators to offer support to PST s following visual methodology in ITE. These approaches provided a means for exploring and maximizing the learning opportunities rather than being constrained by these unprecedented circumstances.

\section{References}

Chan, K., Xu, L., Cooper, R., Berry, A., \& van Driel, J. (2020). Teacher noticing in science education: Do you see what I see? Studies in Science Education. Advance online publication. https://doi.org/10.108o/03057267.2020.1755803.

Chien, C-W. (2015). Pre-service English teachers' perceptions and practice of field experience and professional learning from expert teachers' mentoring. Teachers and Teaching, 21(3), 328-345. https://doi.org/10.1080/135406o2.2014.953817.

Cochran-Smith, M., \& Lytle, S. (1999). Relationships of knowledge and practice:Teacher learning in communities. Review of Research in Education, 24, 249-305. https://doi. org/10.2307/1167272.

Craib, I. (1992). Modern social theory: From Parsons to Habermas. Harvester Wheatsheaf.

Derry, S., Pea, P., Barron, B., Engle, R., Erickson, F., Goldman., et al (2010). Conducting video research in the learning sciences: Guidance on selection, analysis, technology and ethics. Journal of the Learning Sciences 19(1), 3-53 https://doi. org/10.1080/10508400903452884.

Devi, A., Makris, C., \& James, M. (2020). Using digital video technology supports the researcher to be a play participant in children's play. Video Journal of Education and Pedagogy, 4(2), 11-139 http//doi.org/10.1163/23644583-00401019. 
Ellis, V., Glackin, M., Heighes, D., Norman, M., Nicol, S., Norris, K., Spencer, I., \& McNicholl, J. (2013). A difficult realisation: The proletarianisation of higher education-based teacher educators. Journal of Education for Teaching, 39(3), 26628o. https://doi.org/10.1080/o26o7476.2013.799845.

Fitzgerald, A., \& Lowe, M. (2020). Acknowledging documentary filmmaking as not only an output but a research process: A case for quality research practice. International Journal of Qualitative Methods. Advance online publication. https:// doi.org/10.1177/16o9406920957462.

Fleer, M. (2008). Using digital video observations and computer technologies in a cultural-historical approach. In M. Hedegaard, \& M. Fleer, with J. Bang \& P. Hviid, (Eds.). Studying Children: A Cultural-Historical Approach. (pp. 104-107). Open University Press.

Fleer, M. (2013). Beyond developmental geology: A cultural-historical theorization of digital visual technologies for studying young children's development. In M. Fleer \& A. Ridgway (Eds.), Visual methodologies and digital tools for researching with young children (pp. 15-34). Springer. https://doi.org/10.1007/978-3-319-01469-2.

Fleer, M., \& Ridgway, A. (2013). Visual methodologies and digital tools for researching with young children. Springer. https://doi.org/10.1007/978-3-319-01469-2.

Grant, C. A. (1997). Critical knowledge, skills, and experiences for the instruction of culturally diverse students: A perspective for the preparation of preservice teachers. In J. Jordan-Irvine (Ed.), Critical knowledge for diverse teachers and learners (pp. 1-26). American Association of Colleges for Teacher Education.

Goldman, R. (2014). Video representations and the perspectivity framework: Epistemology, ethnography, evaluations and ethics. In R. Goldman, R. Pea, B. Barron \& S. Derry (Eds.), Video research in the learning sciences (pp. 3-38). Routledge.

Hedegaard, M. (2008). A cultural-historical theory of children's development. In M. Hedegaard, \& M. Fleer, with J. Bang \& P. Hviid, (Eds.). Studying Children: A Cultural-Historical Approach. (pp. 20-29). Open University Press.

Hedegaard, M. (2012). Analysing children's learning and development in everyday settings from a cultural-historical wholeness approach. Mind, Culture, and Activity, 19(2), 127-138. http//doi:10.108o/10749039.2012.66556o.

Lampert, M., \& Ball, D. (1998). Teaching, multimedia, and mathematics: Investigations of real practice. Teachers College Press.

Pink, S., Lingard, H., \& Harley, J. (2016). Digital pedagogy for safety: The construction site as a collaborative learning environment. Video Journal of Education and Pedagogy, 1(5), 1-15. https//doi.org/10.1186/s4099o-016-ooo7-y.

Ridgway, A., Li, L., \& Quinones, G. (2016). Visual narrative methodology in education research with babies: Triadic play in babies. Video Journal of Education and Pedagogy, 1, Article 1. https://doi.org/10.1186/s4099o-o16-ooo5-o. 
Vygotsky, L. S. (1997). The collected works of L. S. Vygotsky: Problems of the theory and history of psychology (R. van de Veer, Trans., Vol. 3). New York, NY: Plenum Press. Vygotsky, L. S. (1998). The collected works of L. S. Vygotsky: (Vol 5), Child Psychology, (M. Hall Translator). In R. W Rieber (Ed.). New York: Plenum Press.

Walton, E., \& Rusznyak, L. (2013). Pre-service teachers' pedagogical learning during practicum placements in special schools. Teaching and Teacher Education, 36, 112120. https://doi.org/10.1016/j.tate.2013.07.011.

Yendol-Hoppey, D., \& Dana, N. F. (2007). The reflective educator's guide to mentoring. Corwin Press. 